\title{
Inactivation of novel coronavirus and alpha variant by photo-renewable $\mathrm{Cu}_{x} \mathrm{O} / \mathrm{TiO}_{2}$ nanocomposites
}

\author{
Tetsu Tatsuma ${ }^{1,2, *}$, Makoto Nakakido ${ }^{1}$, Takeshi Ichinohe ${ }^{3, *}$, Yoshinori Kuroiwa ${ }^{2}$, \\ Kengo Tomioka ${ }^{4}$, Chang $\mathrm{Liu}^{4}$, Nobuhiro Miyamae ${ }^{4}$, Tatsuya Onuki ${ }^{1}$, Kouhei Tsumoto ${ }^{1,3, *}$, \\ Kazuhito Hashimoto ${ }^{1}$ and Toru Wakihara ${ }^{1}$
}

${ }^{1}$ School of Engineering, The University of Tokyo, 7-3-1, Hongo, Bunkyo-ku, Tokyo 113-8656, Japan

${ }^{2}$ Institute of Industrial Science, The University of Tokyo, 4-6-1 Komaba, Meguro-ku, Tokyo 1538505, Japan

${ }^{3}$ Institute of Medical Science, The University of Tokyo, 4-6-1 Shirokanedai, Minato-ku, Tokyo 108-8639, Japan

${ }^{4}$ Nippon Paint Holdings Co., Ltd., 4-1-15 Minamishinagawa, Shinagawa-ku, Tokyo 140-8675, Japan

\begin{abstract}
In order to reduce infection risk of novel coronavirus (SARS-CoV-2), we developed photocatalysts with nanoscale rutile $\mathrm{TiO}_{2}(4-8 \mathrm{~nm})$ and $\mathrm{Cu}_{x} \mathrm{O}(1-2 \mathrm{~nm}$ or less). Their extraordinarily small size leads to high dispersity and good optical transparency, besides large active surface area. Those photocatalysts can be applied to white and translucent latex paints and a transparent varnish. Although $\mathrm{Cu}_{2} \mathrm{O}$ clusters involved in the paint coating undergo gradual aerobic oxidation in the dark, the oxidized clusters are re-reduced under $>380 \mathrm{~nm}$ light. The paint coating inactivated novel coronavirus and its alpha (B.1.1.7) variant under irradiation with fluorescent light for $3 \mathrm{~h}$. The coating also exhibited antivirus effects on influenza A virus, feline calicivirus and bacteriophage $Q \beta$. The photocatalysts would be applied to practical coatings and lower the risk of coronavirus infection via solid surfaces.
\end{abstract}

\section{Introduction}

Coronavirus disease 2019 (COVID-19) was first reported as a pneumonia of unknown cause in December 2019, and its pathogen was identified as a novel coronavirus (SARS-CoV2 ) in January 2020. The disease caused an outbreak, and the World Health Organization (WHO) declared a pandemic in March 2020. The coronavirus is characterized by its strong infectivity. Some of the mutation variants are known to be more infectious, and were classified as variants of concern. The most majour pathway of the COVID-19 transmission is believed to be airborne aerosol including viruses from infected persons. However, there are also pathways via solid surfaces including walls, doorknobs, handrails and furniture ${ }^{1}$. Removal of viruses from 
the surfaces would therefore reduce the risk of transmission of the disease. Photocatalyst is one of the promising materials for virus removal. A decade ago, Hashimoto and co-workers ${ }^{2,3}$ reported that $\mathrm{TiO}_{2}$ photocatalysts modified with $\mathrm{Cu}_{x} \mathrm{O}$ inactivate bacteriophage $\mathrm{Q} \beta$. The $\mathrm{Cu}_{x} \mathrm{O} / \mathrm{TiO}_{2}$ composites absorb visible light and electrons are excited from the $\mathrm{TiO}_{2}$ valence band (VB) to $\mathrm{Cu}(\mathrm{II})$, and $\mathrm{Cu}(\mathrm{II})$ is reduced to $\mathrm{Cu}(\mathrm{I})$, which inactivates bacteriophage. The positive holes generated in the $\mathrm{TiO}_{2} \mathrm{VB}$ take electrons from ambient water, so that $\mathrm{TiO}_{2}$ is initialized. Although $\mathrm{Cu}(\mathrm{I})$ in $\mathrm{Cu}_{x} \mathrm{O}$ is ready to be oxidized back to $\mathrm{Cu}(\mathrm{II})$ by ambient oxygen, the $\mathrm{Cu}_{x} \mathrm{O}$ with $\mathrm{Cu}(\mathrm{I})$ is renewed under illumination on the basis of the photocatalytic effect mentioned above.

With these mechanisms in mind, we developed novel photocatalysts that inactivate the novel coronavirus and its variant, as well as some other viruses. White and translucent paint coatings and transparent varnish coatings containing those photocatalysts were also developed. In the previous work, a rutile $\mathrm{TiO}_{2}$ powder of $0.1-0.3 \mu \mathrm{m}$ or larger in size was used as a typical base semiconductor material, and $\mathrm{Cu}_{x} \mathrm{O}$ nanoparticles of $\sim 5-8 \mathrm{~nm}$ diameter were deposited onto the $\mathrm{TiO}_{2}$ powder,3. Considering its large composite size and high refractive index of rutile $\mathrm{TiO}_{2}$ of 2.5-3.0 in the visible wavelength range ${ }^{4}$, the composite particles should tend to settle in a dispersion ${ }^{5}$ and reflect or scatter visible light.

In the present work, we employed a sol containing rutile $\mathrm{TiO}_{2}$ nanoparticles of $\sim 4-8 \mathrm{~nm}$ in size, and deposited $\mathrm{Cu}_{x} \mathrm{O}$ clusters of $<2 \mathrm{~nm}$ in size to develop phtocatalysts with a high active surface area. In addition, because of the nanoscale particle size, we can fabricate translucent or transparent coatings, films and solid substrates containing the photocatalysts, which possess high designability and allow one to irradiate them both from the frontside and backside. An additional advantage of the small nanoparticles is high suspendability without sedimentation, because sedimentation velocity of nanoparticles smaller than $10-100 \mathrm{~nm}$ is negligibly low ${ }^{5}$. This is important point because only photocatalysts exposed at the coating surface are expected to affect viruses. The present sol-based wet process with nanoparticles for preparing photocatalyst coatings would allow various types of antivirus materials including paints, varnishes, gels and spray liquids to be developed. A sol containing anatase $\mathrm{TiO}_{2}$ nanoparticles $(\sim 10 \mathrm{~nm})$ was also used in the present study in place of the rutile $\mathrm{TiO}_{2}$ sol.

\section{Results and discussion}

A rutile $\mathrm{TiO}_{2}$ slurry (Tayca TS-310, $\mathrm{TiO}_{2}$ diameter $\sim 4-8 \mathrm{~nm}$ ) and an anatase $\mathrm{TiO}_{2}$ slurry (Taki Chemical $\mathrm{M}-6, \mathrm{TiO}_{2}$ diameter $\sim 10 \mathrm{~nm}$ ) were employed as base semiconductor materials, and aqueous solutions of $\mathrm{CuCl}_{2}$, glucose as a reducing agent and $\mathrm{NaOH}$ were added to either of the slurries. The mol ratio of $\mathrm{Cu}$ to Ti was 1/20, unless otherwise noted (concentrations: 437 or $404 \mathrm{mM} \mathrm{TiO}$; 62 or $57 \mathrm{mM}$ glucose; 47 or $48 \mathrm{mM} \mathrm{NaOH}$; 22 or $20 \mathrm{mM} \mathrm{CuCl}_{2}$ for rutile and anatase, respectively). We raised its temperature to $90{ }^{\circ} \mathrm{C}$ and stirred it for $1 \mathrm{~h}$ to reduce $\mathrm{Cu}(\mathrm{II})$ ions to $\mathrm{Cu}(\mathrm{I})$ and deposit $\mathrm{Cu}_{x} \mathrm{O}$, a mixture of $\mathrm{Cu}_{2} \mathrm{O}$ and $\mathrm{CuO}$, onto $\mathrm{TiO}_{2}$ nanoparticles. As a 
result, dark suspensions were obtained. In the case of the rutile-based suspension, its colour was a greenish gray (Figure 1a), and its difference spectrum after the deposition was characterized by absorption at 400-500 nm and a broad peak at $\sim 800 \mathrm{~nm}$ (Figure 1b). The latter broad peak suggests that the suspension contains excess $\mathrm{Cu}^{2+}$ ions. Since the former absorption band appears to be due to a semiconductor, we examined Tauc plots and obtained the band-gap values of $\sim 3.0$ and $\sim 2.8 \mathrm{eV}$ on the assumption of the direct and indirect transitions, respectively. Because $\mathrm{Cu}_{2} \mathrm{O}$ and $\mathrm{CuO}$ have been reported to have direct allowed transition band-gap of 2.1-2.6 eV and indirect allowed transition band-gap of 1.2-1.6 eV, respectively ${ }^{6-10}$, we conclude that the optical behaviour observed in the short wavelength range, from which absorption of $\mathrm{TiO}_{2}$ has been excluded, is attributed mainly to $\mathrm{Cu}_{2} \mathrm{O}$. The wider bandgap in comparison with bulk $\mathrm{Cu}_{2} \mathrm{O}$ could be due to the quantum-size effect, as discussed later.

(a)

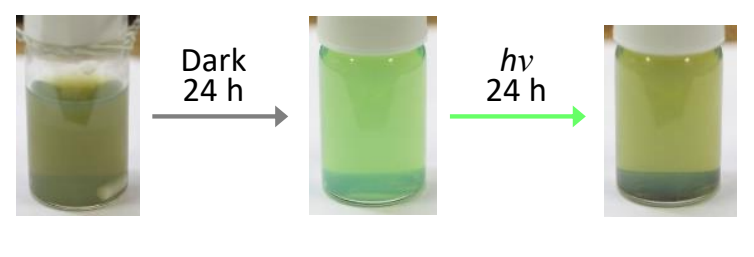

(c)

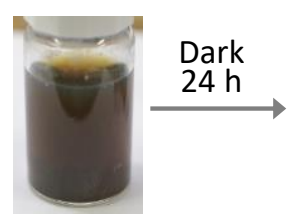

(d)

(e)
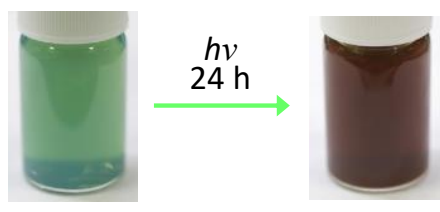

(f)

(g)

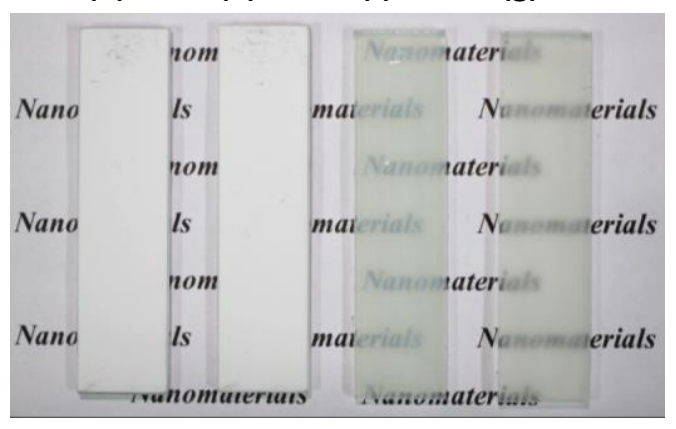

(b)

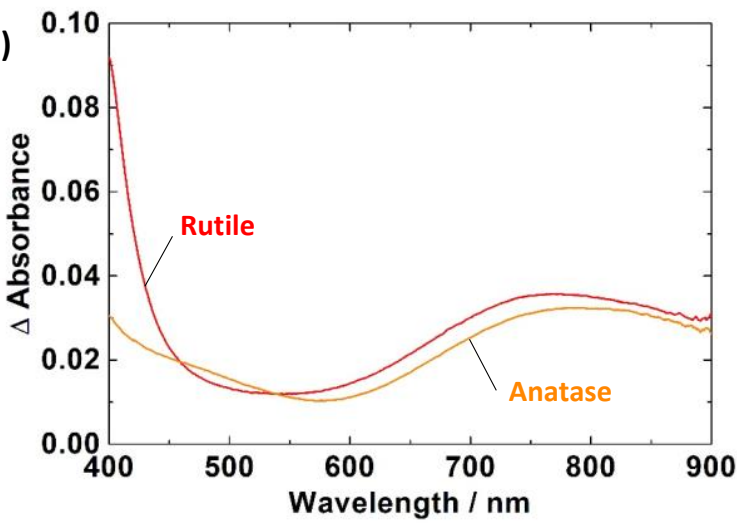

(h)

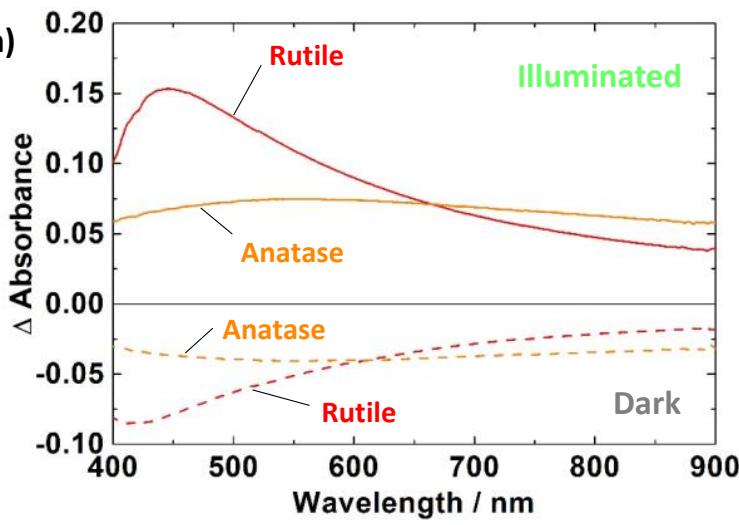

Figure 1. Colour and spectral changes of the photocatalysts. (a, c) Colour changes of the (a) rutile- and (c) anatase-based photocatalyst suspensions after leaving in the dark and under irradiation with simulated solar light. (b) Spectra of the as-prepared photocatalyst suspensions. $(d-g)$ Photographs of the $(d, f)$ rutile- and $(e, g)$ anatase-based photocatalyst coating $(d, e)$ with or (f, $g$ ) without white pigments. (h) Spectral changes of the rutile- and anatase-based coatings in the dark and under illumination (fluorescent light, >380 nm, $500 \mathrm{~lx}$ ).

The anatase-based suspension showed a brownish gray colour (Figure 1c) and an 
absorption band at 400-600 nm (Figure 1b). The corresponding Tauc plots show that the bandgap is $\sim 2.9 \mathrm{eV}$ for direct transition and $\sim 1.7$ or $\sim 2.3 \mathrm{eV}$ for indirect transition. The optical behaviour could therefore be ascribed to both $\mathrm{Cu}_{2} \mathrm{O}$ and $\mathrm{CuO}$.

We also subjected the rutile-based suspension to scanning transmission electron microscopy (STEM; JEM-ARM200F Thermal FE STEM, JEOL) and energy dispersive X-ray spectroscopy (EDS; DRY SD100GV, JEOL) after thorough evaporation of water (Figure 2). The STEM image (Figure 2a) shows that the primary size of the nanoparticles is smaller than $10 \mathrm{~nm}$. As a result of elemental mapping based on STEM-EDS analysis (Figure $2 \mathrm{~d}-\mathrm{f}$ ), we found that the majour component was $\mathrm{TiO}_{2}$ nanoparticles of $\sim 4-8 \mathrm{~nm}$ in size, and that clusters of $\mathrm{Cu}$ compounds (1-2 nm or less) were deposited on $\mathrm{TiO}_{2}$. High resolution HAADF-STEM analysis proved that the $\mathrm{TiO}_{2}$ nanoparticles were rutile phase and that the $\mathrm{Cu}$ compound clusters contained both $\mathrm{Cu}_{2} \mathrm{O}$ and $\mathrm{CuO}$ (Figure $2 \mathrm{~b}, \mathrm{c}$ ). The quantum-sized $\mathrm{Cu}_{2} \mathrm{O}^{11,12}$ justifies its widened band-gap of $\sim 3.0 \mathrm{eV}$ mentioned above due to a quantum-size effect.
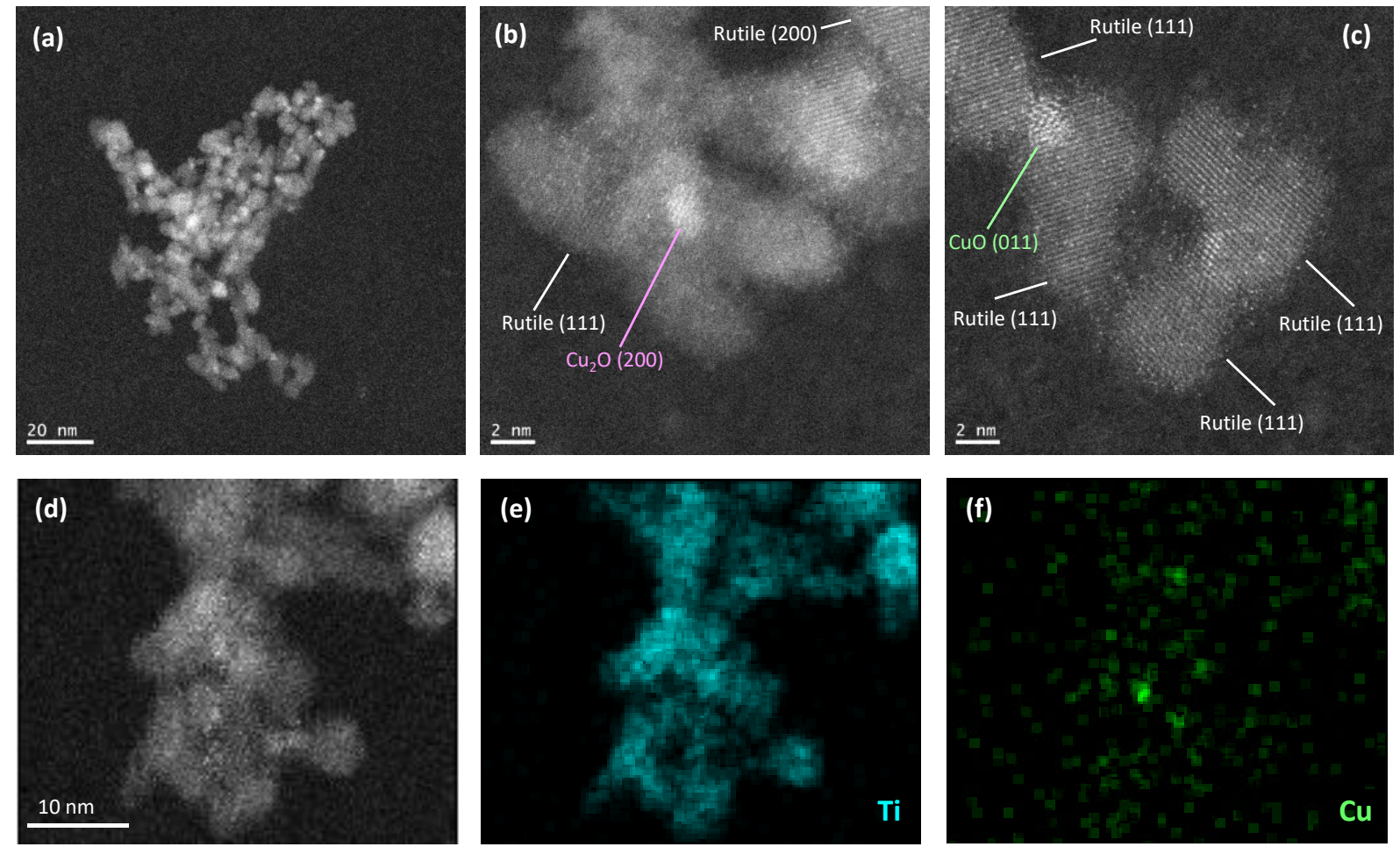

Figure 2. Photocatalyst nanoparticles. (a-d) HAADF-STEM images of the photocatalysts. (e, f) STEM-EDS elemental mapping images for (e) Ti and (f) $\mathrm{Cu}$.

When the suspensions were left in the dark, their colour was gradually changed to green in $24 \mathrm{~h}$ (Figure 1a, c), suggesting that $\mathrm{Cu}_{2} \mathrm{O}$ was oxidized to $\mathrm{Cu}^{2+}$ by dissolved oxygen (Figure 3 , Process A). However, when we irradiated the oxidized suspensions with light from a solar simulator (AM1.5, 100 mW cm-2; BSS-T150, Bunko Keiki) for $24 \mathrm{~h}$, their colour was changed again to greenish gray (Figure 1a) and brownish gray (Figure 1c) for rutile- and anatase-based 
photocatalysts, indicating that $\mathrm{Cu}^{2+}$ was reduced back to $\mathrm{Cu}_{2} \mathrm{O}$. This reduction can be explained in terms of photo-induced interfacial charge transfer from the $\mathrm{TiO}_{2} \mathrm{VB}$ to $\mathrm{Cu}^{2+}$ at the $\mathrm{TiO}_{2}$ surface (Figure 3, Process $\mathrm{B}$ ). ${ }^{2}$ Resultant holes in the $\mathrm{TiO}_{2} \mathrm{VB}$ should be consumed by oxidation of water to oxygen. Electrons in the $\mathrm{TiO}_{2} \mathrm{VB}$ could also be excited to the conduction band (CB) under the simulated solar light, which contains weak UV light, and the excited electrons could also contribute to the reduction of $\mathrm{Cu}^{2+}$ (Figure 3, Process $\mathrm{C}$ ). In the case where the mol ratio of $\mathrm{Cu}$ to Ti was $1 / 100$ or lower, a small absorption peak was observed at $\sim 580 \mathrm{~nm}$ after irradiation of the anatase-based photocatalyst. This could be due to localized surface plasmon resonance (LSPR) of over-reduced, metallic Cu nanoparticles. Plasmonic nanoparticles in contact with $\mathrm{TiO}_{2}$ inject electrons to the $\mathrm{TiO}_{2}$ conduction band, and metal is oxidized to metal ions, in the case of $\mathrm{Ag}$ or less noble metals including $\mathrm{Cu}$ (Figure 3, Process D). ${ }^{13,14}$

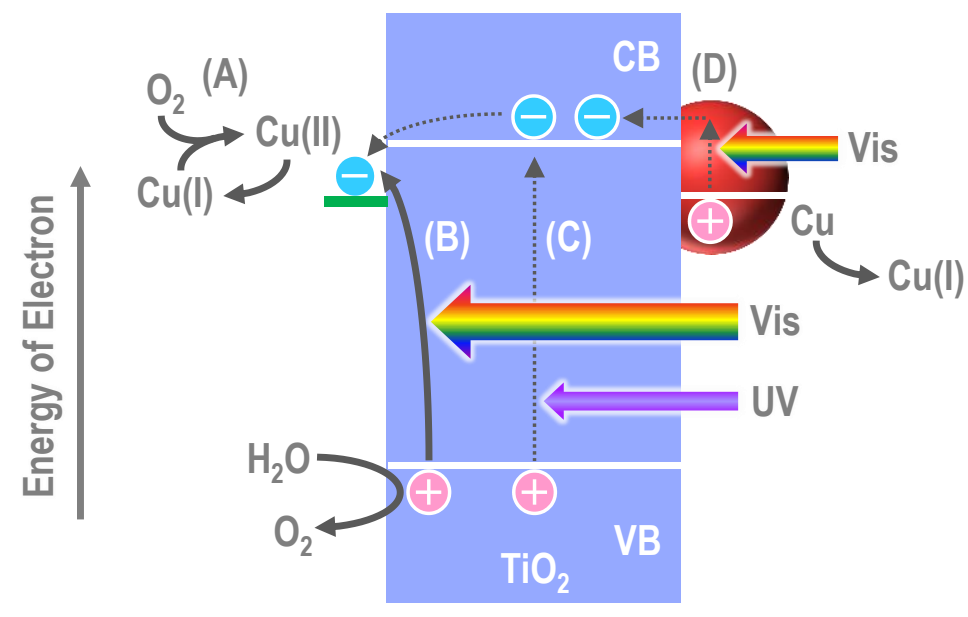

Figure 3. Photoinduced chemical processes involved in the present photo-renewable system.

Either of the $\mathrm{Cu}_{x} \mathrm{O} / \mathrm{TiO}_{2}$ suspensions was added to a latex paint containing inorganic white pigments and organic binders, followed by 5-min stirring and 1-min degassing. Each photocatalyst slurry thus obtained was applied onto a glass plate $\left(0.01 \mathrm{~mL} \mathrm{~cm}^{-2}\right)$. Solvent in the coating was evaporated at $25^{\circ} \mathrm{C}$ for 7 days, and white films were obtained (Figure 1d, e). Colourless translucent films without the white pigment (Figure 1f, g) were also prepared for spectroscopic measurements. Their average thickness was $50 \mu \mathrm{m}$ for both photocatalyst films. We also applied the photocatalysts to a varnish and successfully obtained transparent photocatalyst coatings. The nanoparticles were distributed almost uniformly in the transparent films, indicating that sedimentation was avoided successfully.

After preparation of the coatings, those were left in the dark. As a result, their absorption in the visible wavelength range was decreased gradually (Figure $1 \mathrm{~h}$ ). In marked contrast, the absorption was gradually increased under irradiation with fluorescent light $(<380 \mathrm{~nm}$ light was cut off). The peak at $440 \mathrm{~nm}$ reflect photo-induced interfacial charge transfer from the $\mathrm{TiO}_{2} \mathrm{VB}$ 
to $\mathrm{Cu}^{2+15,16}$. The absorption decrease in the dark and the increase under illumination can be explained in terms of aerobic oxidation (Figure 3A) and photocatalytic re-reduction (Figure 3B), respectively, of $\mathrm{Cu}_{x} \mathrm{O}$ clusters.

The photocatalyst paint coatings were subjected to inactivation tests against novel coronavirus (SARS-CoV-2, wild type) according to the procedures given in International Organization for Standardization ISO 21702 with some modifications. Coronaviruses in 5\% FBS DMEM medium $(25 \mu \mathrm{L})$ were applied onto a glass plate $(20 \times 20 \mathrm{~mm})$ coated with the rutile- or anatase-based photocatalyst coating. The plate was covered with a polypropylene film of the same size and was incubated under fluorescent lamp illumination (1000 Ix) for $3 \mathrm{~h}$, followed by evaluation of viral infectivity $V$ (in pfu) by a plaque assay. Figure 4 a shows the $\log V$ values together with those for control experiments in which a bare glass plate or a glass plate coated with the paint without photocatalyst was used instead of the photocatalytic plate. The rutile-based coating strongly inactivated the novel coronavirus and the obtained viral infectivity was lower than the detection limit of $5 \mathrm{pfu}$. Its antivirus activity $\left[=(\log V)_{\text {ave }}-\left(\log V_{0}\right)_{\text {ave, }}\right.$ where $V_{0}$ is viral infectivity for a bare glass plate and subscript ave stands for averaged values) is 3.5 or higher. The coronavirus can also be inactivated by the anatase-based coating, whereas its antivirus activity is lower (1.7). This difference should be due to the less prominent interfacial charge transfer band at $440 \mathrm{~nm}$ for the anatase-based photocatalyst in comparison with the rutile-based one (Figure $1 \mathrm{~h})$. The larger band-gap of anatase $\mathrm{TiO}_{2}(3.2 \mathrm{eV})$ than rutile $(3.0 \mathrm{eV})$, which lowers the contribution of the $\mathrm{Cu}^{2+}$ reduction pathway via the $\mathrm{TiO}_{2} \mathrm{CB}$ (Figure $3 \mathrm{C}$ ), may also be responsible for the activity difference.

Next we examined an antivirus effect under illumination of the rutile-based coating on alpha variant (also known as lineage B.1.1.7 or VOC-202012/01) of the novel coronavirus, which has mutations including N501Y. We found that its antivirus activity is at least 1.5; the photocatalyst coating can inactivate alpha variant. We also subjected the photocatalyst coating to antivirus assays for other viruses by Kitasato Research Center for Environmental Science. Figure 4b shows the results for bacteriophage $Q \beta$ obtained by the protocol of Japanese Industrial Standard JIS R1756. The antivirus activities evaluated for the rutile- and anatase-based coatings were $\geq 5.0$ and 3.4 , respectively. Antivirus effects on influenza A virus and feline calicivirus, which is often used as a surrogate for norovirus because of the similarity in terms of a capsid-enveloped structure, were investigated in the dark, according to the protocol of ISO 21702. We observed significant inactivation effects of the rutile- and anatase-based photocatalyst coatings after $24-\mathrm{h}$ incubation. The coatings were subjected to assay 18 days after the synthesis of the photocatalysts. We therefore conclude that $\mathrm{Cu}_{2} \mathrm{O}$ remaining in the coating caused the antivirus effects because $\mathrm{Cu}_{2} \mathrm{O}$ has been known to inactivate bacteriophage $Q \beta^{17,18}$ and influenza virus ${ }^{18}$. 


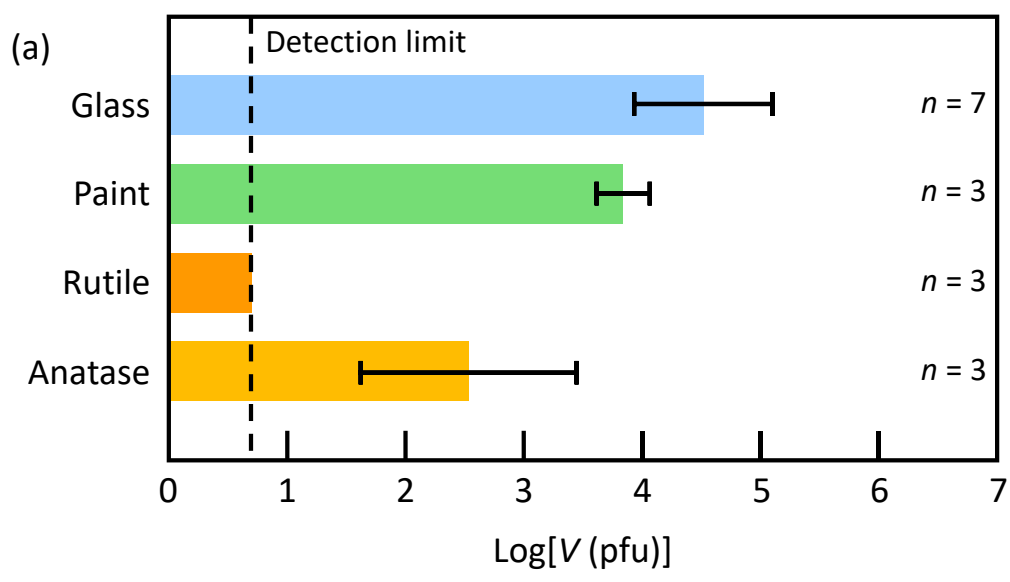

(b)

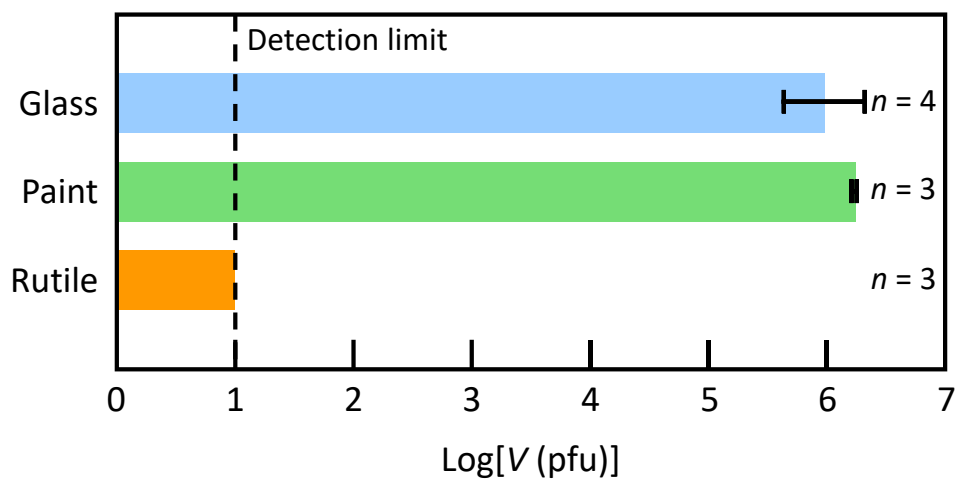

Figure 4. Antivirus effects of the rutile- and anatase-based photocatalyst coatings. The employed coatings exhibited antivirus effects on (a) the wild type novel coronavirus and (b) bacteriophage $Q \beta$ during incubation under fluorescent light (1000 Ix for $3 \mathrm{~h}$ for coronavirus and $500 \mathrm{Ix}$ for $4 \mathrm{~h}$ for bacteriophage).

Since previous studies have shown that $\mathrm{Cu}_{2} \mathrm{O}$ inactivates influenza virus through denaturation of hemagglutinin at the virus surface ${ }^{18}$, we investigated if the photocatalysts containing $\mathrm{Cu}_{2} \mathrm{O}$ developed in this study denature the surface spike protein, which has a critical role in infection ${ }^{19}$, and thereby suppress infectivity of novel coronavirus. To assess this, we prepared recombinant protein of the receptor binding domain (RBD) of spike protein and evaluated the denaturation effects of the photocatalysts on the protein. Since the binding of RBD to human ACE2, the receptor for coronavirus, is an essential step in the infection ${ }^{19}$, the 5 $\mu \mathrm{M}$ recombinant $\mathrm{RBD}$ protein $(70 \mu \mathrm{L})$ was mixed with the photocatalyst suspensions $(70 \mu \mathrm{L})$ and left for $2 \mathrm{~h}$ at $4{ }^{\circ} \mathrm{C}$ and the binding activity toward ACE2 was examined by enzyme-linked immuno-sorbent assay (ELISA) according to literature ${ }^{20}$. As shown in Figure 5, the binding activity of RBD to ACE2 was significantly diminished by the incubation with the photocatalysts, indicating that the photocatalysts denatured the RBD protein. These results strongly support our conclusion that the antiviral effect of the photocatalyst on coronavirus relies, at least in part, on the protein denaturing activity. Further study to reveal the denaturing process of the proteins will provide a strategy to develop photocatalysts with even higher antiviral activity. 


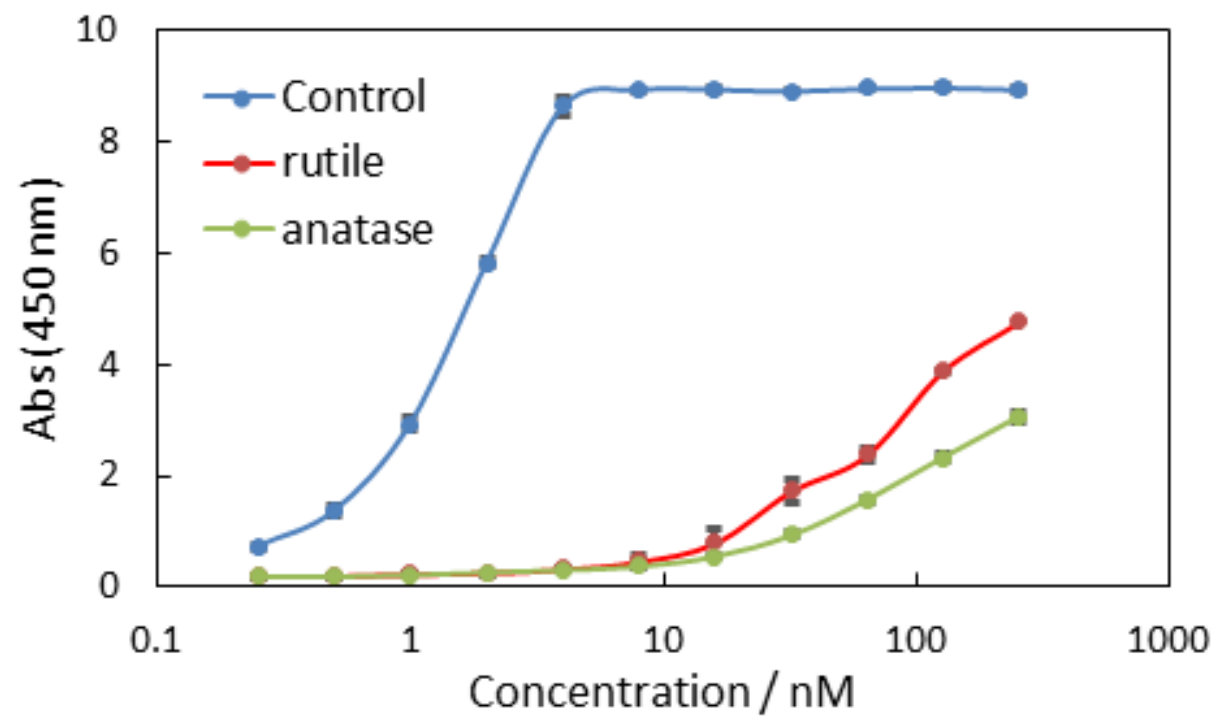

Figure 5. Denaturation effect of the rutile- and anatase-based photocatalysts on RBD domain of spike protein from coronavirus. The binding activity of RBD to human ACE2 protein at various concentrations was assessed by ELISA.

\section{Acknowledgments}

The authors are grateful to Dr. T. Ishida and Advanced Characterization Nanotechnology Platform, The University of Tokyo for HAADF-STEM and STEM-EDS measurements. Those measurements were supported in part by a Nanotechnology Platform project by the Ministry of Education, Culture, Sports, Science and Technology of Japan (No. JPMXP09A21UT0198).

\section{References}

1. N. H. L. Leung, Transmissibility and transmission of respiratory viruses. Nature Rev. Microbiol., 19, 528 (2021).

2. X. Qiu, M. Miyauchi, K. Sunada, M. Minoshima, M. Liu, Y. Lu, D. Li, Y. Shimodaira, Y. Hosogi, $\mathrm{Y}$. Kuroda and $\mathrm{K}$. Hashimoto, Hybrid $\mathrm{Cu}_{x} \mathrm{O} / \mathrm{TiO}_{2}$ nanocomposites as risk-reduction materials in indoor environments. ACS Nano, 6, 1609 (2012).

3. M. Liu, K. Sunada, K. Hashimoto and M. Miyauchi, Visible-light sensitive $\mathrm{Cu}(\mathrm{II})-\mathrm{TiO}_{2}$ with sustained anti-viral activity for efficient indoor environmental remediation. J. Mater. Chem. A, 3, 17312 (2015).

4. J. R. Devore, Refractive indices of rutile and sphalerite. J. Opt. Soc. Am., 41, 416 (1951).

5. J. K. G. Dhont, An introduction to dynamics of colloids. Elsevier, Amsterdam, 1996.

6. J. Ghijsen, L. H. Tjeng, J. van Elp, H. Eskes, J. Westerink, G. A. Sawatzky and M. T. Czyzyk, Electronic structure of $\mathrm{Cu}_{2} \mathrm{O}$ and CuO. Phys. Rev. B, 38, 11322 (1988).

7. F. P. Koffyberg and F. A. Benko, A photoelectrochemical determination of the position of the conduction and valence band edges of p-type CuO. J. Appl. Phys., 53, 1173 (1982).

8. T. Ito, H. Yamaguchi, T. Masumi and S. Adachi, Optical properties of CuO ptudied by 
spectroscopic ellipsometry. J. Phys. Soc. Jpn., 67, 3304 (1988).

9. Y. Wang, P. Miska, D. Pilloud, D. Horwat, F. Mücklich and J. F. Pierson, Transmittance enhancement and optical band gap widening of $\mathrm{Cu}_{2} \mathrm{O}$ thin films after air annealing. J. Appl. Phys., 115, 073505 (2014).

10. Y. Wang, S. Lany, J. Ghanbaja, Y. Fagot-Revurat, Y. P. Chen, F. Soldera, D. Horwat, F. Mücklich and J. F. Pierson, Electronic structures of $\mathrm{Cu}_{2} \mathrm{O}, \mathrm{Cu}_{4} \mathrm{O}_{3}$, and $\mathrm{CuO}$ : $\mathrm{A}$ joint experimental and theoretical study. Phys. Rev. B, 94, 245418 (2016).

11. A. Kellersohn, E. Knözinger, W. Langel and M. Giersig, $\mathrm{Cu}_{2} \mathrm{O}$ quantum-dot particles prepared from nanostructured copper. Adv. Mater., 7, 652 (1995).

12. K. Borgohain, N. Murase and S. Mahamuni, Synthesis and properties of $\mathrm{Cu}_{2} \mathrm{O}$ quantum particles. J. Appl. Phys., 92, 1292 (2002).

13. Y. Tian and T. Tatsuma, Mechanisms and applications of plasmon-induced charge separation at $\mathrm{TiO}_{2}$ films loaded with gold nanoparticles. J. Am. Chem. Soc., 127, 7632 (2005).

14. T. Tatsuma, H. Nishi and T. Ishida, Plasmon-induced charge separation: chemistry and wide applications. Chem. Sci., 8, 3325 (2017).

15. H. Irie, S. Miura, K. Kamiya and K. Hashimoto, Efficient visible light-sensitive photocatalysts: Grafting $\mathrm{Cu}(\mathrm{II})$ ions onto $\mathrm{TiO}_{2}$ and $\mathrm{WO}_{3}$ photocatalysts. Chem. Phys. Lett., 457, 202 (2008).

16. H. Irie, K. Kamiya, T. Shibanuma, S. Miura, D. A. Tryk, T. Yokoyama and K. Hashimoto, Visible light-sensitive $\mathrm{Cu}(\mathrm{II})$-grafted $\mathrm{TiO}_{2}$ photocatalysts: activities and X-ray absorption fine structure analyses. J. Phys. Chem. C, 113, 10761 (2009).

17. K. Sunada, M. Minoshima and K Hashimoto, Highly efficient antiviral and antibacterial activities of solid-state cuprous compounds. J. Hazard. Mater., 235-236, 265 (2012).

18. M. Minoshima, Y. Lu, T. Kimura, R. Nakano, H. Ishiguro, Y. Kubota, K. Hashimoto and K. Sunada, Comparison of the antiviral effect of solid-state copper and silver compounds, $J$. Hazard. Mater., 312, 1 (2016).

19. H. Yao, Y. Song, Y. Chen, N. Wu, J. Xu, C. Sun, J. Zhang, T. Weng, Z. Zhang, Z. Wu, L. Cheng, D. Shi, X. Lu, J. Lei, M. Crispin, Y. Shi, L. Li and S. Li, Molecular architecture of the SARS-CoV-2 virus. Cell, 183, 730 (2020).

20. C. W. Tan, W. N. Chia, X. Qin, P. Liu, M. I.-C. Chen, C. Tiu, Z. Hu, V. C.-W. Chen, B. E. Young, W. R. Sia, Y.-J. Tan, R. Foo, Y. Yi, D. C. Lye, D. E. Anderson and L.-F. Wang, A SARS-CoV-2 surrogate virus neutralization test based on antibody-mediated blockage of ACE2-spike protein-protein interaction. Nat. Biotechnol., 38, 1073 (2020). 